\title{
SOME PITFALLS IN THE DIAGNOSIS AND TREATMENT OF INHERITED SYPHILIS
}

\section{Discussion}

The President said the Society was very grateful to Dr. Nabarro for the very comprehensive manner in which he had dealt with this very important subject. The reader apologised for the historical introduction to the subject, but the speaker assured him that this part was highly appreciated, and when it appeared in the JouRNAL it would be very valuable for reference. There could be no doubt as to the value of the rest of the paper.

Dr. JoHn ADAms agreed with the President's expressions of appreciation concerning Dr. Nabarro's paper. It was sheer modesty to say that the paper was possible because others had sent him cases to report on.

He would like to know what were Dr. Nabarro's methods of treating infants with congenital syphilis in the very earliest stages. The speaker had been very fortunate, for in I9I7 the Metropolitan Asylums Board gave him a hospital with a free hand to treat the mothers ante-natally and post-natally. There could be no comparison, in the matter of results, between these two methods. Ante-natal treatment was of great importance. If all mothers had been treated anti-syphilitically as a routine, Dr. Nabarro would not have had half so many cases, and most of the children would have been free from syphilis when born. Once a mother had had syphilis, whatever her blood reaction might be, she should have a course of treatment commencing not later than the fifth month in future pregnancies. Though he had had over 300 cases of syphilitic pregnant women under his care, he saw but little in the way of secondary manifestations of syphilis. If mother and child were attended to early, these manifestations between the first and the tenth years were seldom, if ever, seen. The early treatment of ante-natal and post-natal syphilis on the lines he had been 


\section{BRITISH JOURNAL OF VENEREAL DISEASES}

carrying out was most successful and encouraging. If the mother had not been treated during pregnancy, the child's positive Wassermann could be rendered negative by early treatment. As soon as a syphilitic infant was born treatment was commended. There was no difficulty about giving the injections; the treatment was an easy matter.

As to the reliability of the tests, he had great confidence in the Wassermann test, as he found the clinical evidence nearly always agreed with the reports. He contended that women in public institutions who were pregnant should have a Wassermann test done, irrespective of the history given. One of Dr. Nabarro's cases had both gonorrhœa and syphilis. He paid, however, great attention to the clinical investigation of cases. Two weeks ago he had a woman who stated that she had no sores about her, but a well-marked primary syphilis was present. The statement was honestly made in the belief that it was true; it showed how little one could rely on the history given. In treating infants and young children the great battle was over in the first two or three months; when, as a rule, the case became negative, then a rest from treatment should be given. Every case of syphilis, whether congenital or acquired, should be under treatment, more or less, for two years. He always laid it down emphatically that no case should have less than a minimum of one year's treatment. The doses he gave to children were a good deal based upon their weight in comparison with that of the mother. When he started this work he had no records to guide him. He had since drawn up a scale of dosage, and had treated cases with salvarsan and mercury practically from the beginning. The mercury was given in $\frac{1}{2}$ gr. tabloids. The tabloid could be broken up and placed on the tongue and then the baby should be given the breast or bottle. In early days mercury was given by intramuscular injection, and not unfrequently caused local trouble, but he had not given it in that way for years. All the effect of mercury could be secured without injection. Mercury should be given just sufficient to show its effects. Even since the discovery of salvarsan one could not do without mercury.

What happened to these children? He had treated over 300 syphilitic children, but very seldom, if ever, saw the development of the later manifestations of the 


\section{TREATMENT OF INHERITED SYPHILIS}

disease. If one treated these mothers sonsiderately and sympathetically they proved to be very good patients, and easy to get on with. For over thirteen years he had held a clinic every other Sunday morning, and the attendances were very regular. Very few of the patients reverted to a positive Wassermann.

The Royal Commission which sat in I9r3 stated that 75 per cent. of untreated syphilitic children died in the first year of life, and most in the first few weeks. He found that though a child might be born blue, because of the syphilitic congestion of the lungs, and odematous because of the disease in the liver, if the child could breathe and treatment was started forthwith, it would almost certainly get better. In the adult there was evidence that the spirochætes were being attacked by the salvarsan within fifteen minutes of giving the drug, shown by the manifestation of Herxheimer's rash due to endotoxines being set free by the action of salvarsan on the spirochætes.

With regard to infant mortality, in the first two years there was a slight mortality; in I9I9 four of the babies died, and one in I928 - a mortality of five in 300-none since. These children, whose mothers had been treated as well as the infants themselves, looked well, and their average weight equalled the ordinary child of the same age.

There was still a deplorable mortality among women in maternity homes. During the past thirteen years 600 women had been confined at Thavies Inn V.D. Centre, many very septic, among them two cases of eclampsia and one of Cæsarean section; rarely were instruments used. Aseptic and ante-septic treatment was strictly carried out before and after confinement, and the result was most satisfactory.

Mr. HAMISH NICOL said he had treated congenital syphilitic cases of fourteen to twenty years of age, and in them it was very difficult to produce a negative Wassermann. He would like to know what line of treatment Dr. Nabarro would adopt in such cases, and how long the treatment should be persisted in. Also, in the case of suspected congenital syphilis in an infant, where it was difficult to get the blood for the Wassermann test, would it not be sufficient to get the blood from the mother for examination? 


\section{BRITISH JOURNAL OF VENEREAL DISEASES}

Mr. S. H. BRowning asked why Dr. Nabarro tested the Wassermann reaction so often in his cases which were known to be syphilitic. He, the speaker, dealt with many cases of interstitial keratitis, and he found it very difficult to procure a negative Wassermann-indeed, he had almost given up hope of doing so. He treated such cases for three years fairly intensively, and he had almost reached the stage of refusing to do Wassermann tests. on them.

Dr. Nabarro found deafness rather a rare accompaniment of syphilis, but the speaker found it often associated with interstitial keratitis. On the other hand, unequal pupils, which Dr. Nabarro found fairly often, he, Mr. Browning, encountered only rarely. $\mathrm{He}$ wondered whether the reader could explain this discrepancy.

What was the ultimate fate of congenital cases with interstitial keratitis? At Moorfields it was rare to find in adults signs of old interstitial keratitis, and the speaker wondered whether the kind of patients he was referring to died in early life.

It was very rare for him to see very young infants with congenital syphilis-eighteen months was his youngest. $\mathrm{He}$ gave them big doses of stabilarsan intramuscularly, apparently about three times as much as did Dr. Nabarro; what was the latter's average amount per course?

Dr. Nabarro spoke of giving these patients the minimum treatment because of the pain they suffered. But if stabilarsan and bismuth were used, pain would not result. He did not get any fatalities among his infants.

The PREsident remarked that one of the points which occurred to him during the reading of Dr. Nabarro's excellent paper was as to the importance of the Wassermann test. When obscure conditions were present in an infant or child, as in the case of the adult, it was always a valuable control to ascertain the result of Wassermann test; cases of syphilis had often been missed through failure to use this diagnostic aid.

Apparently, Dr. Nabarro and Dr. Adams agreed that the best way to deal with congenital syphilis was to prevent it occurring by dealing with the mothers during pregnancy. That this was being done so largely now was, to a man who had been engaged in public health work all his life, a very encouraging sign of the times. The more 


\section{TREATMENT OF INHERITED SYPHILIS}

medicine was made preventive, the better; and it was refreshing to find physicians like Dr. Nabarro and Dr. Adams advocating the prevention of disease instead of waiting until it developed and then treating it.

He would like to hear from Dr. Nabarro what happened to the treated children who had congenital syphilis as regards their physical and mental development. One case which had been mentioned showed that a good deal of interference with physical growth might occur, and he asked whether it was Dr. Nabarro's experience that children who had suffered from congenital syphilis were more apt to be mentally dull or to suffer from idiocy or other mental conditions than were other children, even if these syphilitic children had been treated properly. Also, could Dr. Nabarro state what proportion of the mental deficiency found in school children was attributable to congenital syphilis ? What had been said about a more adequate search being made among school children for traces of congenital syphilis was very important.

If syphilis in the child was not prevented by adequate treatment of the mother, certainly the earlier the treat- ment of the child was commenced, the better.

Considerable difference of opinion was found among school medical officers as to the proportion of congenital syphilitics revealed by school medical inspections. Perhaps these differences might partly be accounted for by

- failure to use all the diagnostic tests available. At one time he, the President, made inquiries in certain counties, and was surprised to learn that in some counties the medical officers found practically no trace of congenital syphilis in the school children, a state of things which seemed too good to be true. In infant welfare and V.D. clinics cases should be sorted out and put under treatment. It was very important that the examinations should be done with uniformity, otherwise statistics - would be far from reliable. He knew of one instance in which an enthusiastic lady doctor found syphilis so frequently that her colleagues became concerned and suggested that cases of rickets were being diagnosed as syphilis.

Dr. NABARRO, in reply, thanked members for their kind reception of his paper.

In reply to Dr. Adams, the treatment of early cases was briefly mentioned in the paper. In the case of very 


\section{BRITISH JOURNAL OF VENEREAL DISEASES}

young patients he did not start at once with arsenical injections if the child was marasmic, as his early experience had shown him that a fatal termination might be precipitated by giving salvarsan too early. He had spoken about it to Dr. Gray, of University College, and he had found the same thing. He, Dr. Nabarro, started with mercury, then gave small injections of stabilarsan or sulphostab.

He agreed with what Dr. Adams said as to the treatment of the mothers; there was no question that the proper way to tackle this subject was by preventive rather than curative measures. Once a syphilitic family was encountered it was one's duty to talk to the mother sympathetically and properly, telling her that should she find she was going to have another baby she should undergo treatment, for the sake of her expected baby as well as for her own. A number of syphilitic mothers bore healthy children, even if the former had not been treated for their syphilis; he had watched such children for a number of years succeeding birth, and clinical and serological tests failed to show they were syphilitic.

He would like to know whether Dr. Adams treated the babies as well as the mothers. (Dr. Adams: Yes.) $\mathrm{He}$ thought that was unscientific; if one treated every syphilitic mother and every child, it would prevent the effect of ante-natal treatment on the mother being properly assessed.

He wondered whether Dr. Adams had seen cases of gonorrhœa with a positive Wassermann. When a person had gonorrhœa he might have syphilis in a masked form, and so he was able to infect his wife, and through her, the,children.

He rarely saw local troubles in these cases. He always tried to avoid treating these children unnecessarily. Children dreaded injections, and he did not inject mercury into them. In addition to the treatment for their syphilis, these children must have proper food: cod-liver oil and vitamins were very helpful. Homes for these juvenile cases would be a great boon.

It had been his experience that it was very difficult for a mother to bring a child up for treatment when there were several other children in the family. Sometimes he got N.S.P.C.C. people to bring the children up to the hospital. 


\section{TREATMENT OF INHERITED SYPHILIS}

In answer to Colonel Harrison, a commencement had been made with the speaker's book; his records had been analysed, and he hoped that by the end of the year they would be published, in the same way as Colonel Harrison's own results were published.

He agreed that children of fourteen to twenty years of age who had a positive Wassermann were very difficult to treat. To such he had given forty to fifty injections, totalling I5 $\mathrm{gm}$. of arsenic compounds, and sometimes added bismuth, especially the oxy-chloride of bismuth. If after fifty injections the Wassermann was still positive, he gave it up as a bad job. Sometimes if a syphilitic child was lost sight of for five or six years, it had a Negative Wassermann when it came back at the end of that time, but he could not say that it was cured. 